\title{
Fibulin-3 Attenuates Phosphate-Induced Vascular Smooth Muscle Cell Calcification by Inhibition of Oxidative Stress
}

\author{
Trang T. D. Luong ${ }^{a}$ Nadeshda Schelskia Beate Boehme ${ }^{a}$ Manousos Makridakis ${ }^{b}$ \\ Antonia Vlahou ${ }^{b}$ Florian Lang ${ }^{c}$ Burkert Pieske ${ }^{a, d, e}$ Ioana Alesutan ${ }^{a, d, f}$ Jakob Voelkla,f \\ aDepartment of Internal Medicine and Cardiology, Charité - Universitätsmedizin Berlin, Germany; \\ 'Biomedical Research Foundation, Academy of Athens, Athens, Greece; 'Department of Physiology

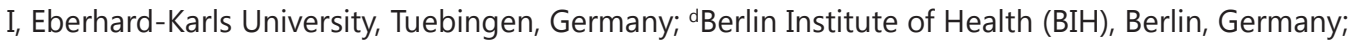 \\ eDepartment of Internal Medicine and Cardiology, German Heart Institute Berlin, Berlin, Germany; \\ fDZHK (German Centre for Cardiovascular Research), partner site Berlin, Berlin, Germany
}

\section{Key Words}

Fibulin-3 $\cdot$ Phosphate $\cdot$ Oxidative stress $\bullet$ Vascular calcification $\bullet$ Osteo-/chondrogenic signaling - Vascular smooth muscle cells

\begin{abstract}
Background/Aims: Fibulin-3, an extracellular matrix glycoprotein, inhibits vascular oxidative stress and remodeling in hypertension. Oxidative stress is prevalent in chronic kidney disease (CKD) patients and is an important mediator of osteo-/chondrogenic transdifferentiation and calcification of vascular smooth muscle cells (VSMCs) during hyperphosphatemia. Therefore, the present study explored the effects of Fibulin-3 on phosphate-induced vascular calcification. Methods: Experiments were performed in primary human aortic smooth muscle cells (HAoSMCs) treated with control or with phosphate without or with additional treatment with recombinant human Fibulin-3 protein or with hydrogen peroxide as an exogenous source of oxidative stress. Results: Treatment with calcification medium significantly increased calcium deposition in HAoSMCs, an effect significantly blunted by additional treatment with Fibulin-3. Moreover, phosphate-induced alkaline phosphatase activity and mRNA expression of osteogenic and chondrogenic markers MSX2, CBFA1, SOX9 and ALPL were all significantly reduced by addition of Fibulin-3. These effects were paralleled by similar regulation of oxidative stress in HAoSMCs. Phosphate treatment significantly up-regulated mRNA expression of the oxidative stress markers NOX4 and CYBA, down-regulated total antioxidant capacity and increased the expression of downstream effectors of oxidative stress PAI-1, MMP2 and $M M P 9$ as well as $B A X / B L C 2$ ratio in HAoSMCs, all effects blocked by additional treatment with Fibulin-3. Furthermore, the protective effects of Fibulin-3 on phosphate-induced osteogenic and chondrogenic markers expression in HAoSMCs were reversed by additional treatment


with hydrogen peroxide. Conclusions: Fibulin-3 attenuates phosphate-induced osteo-/ chondrogenic transdifferentiation and calcification of VSMCs, effects involving inhibition of oxidative stress. Up-regulation or supplementation of Fibulin-3 may be beneficial in reducing the progression of vascular calcification during hyperphosphatemic conditions such as CKD.

(C) 2018 The Author(s)

Published by S. Karger AG, Basel

\section{Introduction}

Fibulin-3 is an extracellular matrix protein $[1,2]$ widely expressed in various tissues [2] including the vasculature [1,3]. The functions of Fibulin-3 include basement membrane organization and elastic fiber formation [4]. It also interacts with other matrix proteins, forming anchoring structures to regulate cell proliferation and migration $[4,5]$. Furthermore, Fibulin-3 promotes angiogenesis [6]. In addition to its role in extracellular matrix organization, Fibulin-3 participates in various intracellular signaling pathways [4, 7-9].

In the media of arterial wall, Fibulin-3 expression is up-regulated at hypertensive vascular remodeling $[3,10]$. Fibulin-3 has previously been suggested as an arterial growth factor $[3,6]$ as injection of Fibulin-3 protein increases aortic wall thickness in spontaneously hypertensive rats [10]. However, Fibulin-3 reduces systolic blood pressure and improves vascular health [10], at least in part, by reducing aortic oxidative stress [10$12]$ and expression of matrix gelatinases $[10,13]$. In vascular smooth muscle cells (VSMCs), gelatinase expression and activity are stimulated by excessive oxidative stress [14-17].

Oxidative stress is commonly associated with cardiovascular disease $[18,19]$ and allcause mortality in patients with chronic kidney disease (CKD) [20]. The high cardiovascular morbidity and mortality of CKD patients is associated with medial vascular calcification [21]. Vascular calcification is an active process promoted by osteo-/chondrogenic reprogramming of VSMCs [22, 23]. Various pathological factors [22, 24-26], most importantly phosphate [27], induce the phenotypical transdifferentiation of contractile VSMCs into osteoblast and chondroblast-like cells via complex signaling pathways. Oxidative stress is an important mediator of osteo-/chondrogenic transdifferentiation of VSMCs [28-30]. These transdifferentiated VSMCs express osteogenic and chondrogenic transcription factors, such as msh homeobox 2 (MSX2), core-binding factor $\alpha-1$ (CBFA1) and SRY-Box 9 (SOX9) [24, 31, 32], as well as osteogenic enzymes, such as tissue non-specific alkaline phosphatase (ALPL) [33] to cause an active mineralization of vascular tissue.

The present study explored the effects of Fibulin-3 protein on phosphate-induced osteo-/chondrogenic transdifferentiation and calcification of VSMCs in-vitro as well as the possible involvement of oxidative stress suppression in mediating these effects.

\section{Materials and Methods}

Cell culture of primary human aortic smooth muscle cells

Primary human aortic smooth muscle cells (HAoSMCs) commercially obtained from Thermo Fisher Scientific were cultured in medium containing a 1:1 ratio of Waymouth's MB 752/1 medium and Ham's F-12 nutrient mixture (Thermo Fisher Scientific) supplemented with $10 \%$ FBS (Thermo Fisher Scientific), $100 \mathrm{U} / \mathrm{ml}$ penicillin and $100 \mu \mathrm{g} / \mathrm{ml}$ streptomycin (Thermo Fisher Scientific) [34, 35]. At least 4 different batches of HAoSMCs were used during the course of this study and each experiment was performed in at least 2 different batches of HAoSMCs at different passages, depending on the availability of the cells. HAoSMCs were grown to confluence and used in all experiments from passages 4 to 10 . HAoSMCs were treated for the indicated periods with $2 \mathrm{mM} \beta$-glycerophosphate (Sigma Aldrich) [23, 28, 34, 36-38], $200 \mathrm{ng} / \mathrm{ml}$ recombinant human Fibulin-3 protein (R\&D Systems) [9, 39] or 10 $\mu \mathrm{M} \mathrm{H}_{2} \mathrm{O}_{2}$ (Sigma Aldrich) [40-42]. Treatment with $10 \mathrm{mM} \beta$-glycerophosphate and $1.5 \mathrm{mM}$ 
$\mathrm{CaCl}_{2}$ (Sigma-Aldrich) for 11 days was used as calcification media for the calcium deposition analysis and Alizarin Red staining [43]. Fresh media with agents were added every 2-3 days.

\section{Analysis of calcification}

To quantify the calcium deposition, HAoSMCs were decalcified in $0.6 \mathrm{M} \mathrm{HCl}$ for 24 hours at $4^{\circ} \mathrm{C}$. Calcium content in the supernatant was determined by using QuantiChrom Calcium assay kit (BioAssay Systems) according to the manufacturer's protocol. HAoSMCs were lysed with $0.1 \mathrm{M} \mathrm{NaOH} / 0.1 \%$ SDS and protein concentration was measured by the Bradford assay (Bio-Rad Laboratories). The results are shown normalized to total protein concentration [44]. To visualize calcification, HAoSMCs were fixed with 4\% paraformaldehyde and stained with 2\% Alizarin Red (pH 4.5). The calcified areas are shown as red staining [28].

Alkaline phosphatase (ALPL) activity assay

ALPL activity in HAoSMCs was determined by using the ALP colorimetric assay kit (Abcam) according to the manufacturer's protocol [35]. The results are shown normalized to total protein concentration measured by the Bradford assay (Bio-Rad Laboratories).

\section{Antioxidant capacity assay}

Total antioxidant capacity of HAoSMCs was measured in the cell lysate by using the colorimetric antioxidant assay kit (Cayman Chemical) according to the manufacturer's protocols. The capacity of the antioxidants in the samples was compared to that of Trolox as standard [28]. The results were normalized to total protein concentration as assessed by the Bradford assay (Bio-Rad Laboratories) and to the control group.

\section{Quantitative RT-PCR}

Total RNA was isolated from HAoSMCs by using Trizol Reagent (Thermo Fisher Scientific) according to the manufacturer's instructions [45-47]. Reverse transcription of $2 \mu \mathrm{g}$ RNA was performed using oligo(dT)12-18 primers (Thermo Fisher Scientific) and SuperScript III Reverse Transcriptase (Thermo Fisher Scientific). Quantitative RT-PCR was performed with the iCycler iQTM Real-Time PCR Detection System (Bio-Rad Laboratories) and iQTM Sybr Green Supermix (Bio-Rad Laboratories) according to the manufacturer's instructions. The following human primers were used $\left(5^{\prime} \rightarrow 3^{\prime}\right.$ orientation):

ALPL fw: GGGACTGGTACTCAGACAACG;

ALPL rev: GTAGGCGATGTCCTTACAGCC;

$B A X$ fw: CCCGAGAGGTCTTTTTCCGAG;

$B A X$ rev: CCAGCCCATGATGGTTCTGAT;

$B C L 2$ fw: GGTGGGGTCATGTGTGTGG;

$B C L 2$ rev: CGGTTCAGGTACTCAGTCATCC;

CBFA1 fw: GCCTTCCACTCTCAGTAAGAAGA;

CBFA1 rev: GCCTGGGGTCTGAAAAAGGG;

CYBA fw: CCCAGTGGTACTTTGGTGCC;

CYBA rev: GCGGTCATGTACTTCTGTCCC;

EFEMP1 fw: TGCAGACTGGCCGAAATAACT;

EFEMP1 rev: CACACTGGATACGGTGGGAA;

GAPDH fw: GAGTCAACGGATTTGGTCGT;

GAPDH rev: GACAAGCTTCCCGTTCTCAG;

$M M P 2 \mathrm{fw}$ : TACAGGATCATTGGCTACACACC;

MMP2 rev: GGTCACATCGCTCCAGACT;

$M M P 9$ fw: AGACCTGGGCAGATTCCAAAC;

MMP9 rev: CGGCAAGTCTTCCGAGTAGT;

$M S X 2 \mathrm{fw}$ : TGCAGAGCGTGCAGAGTTC;

MSX2 rev: GGCAGCATAGGTTTTGCAGC;

NOX4 fw: TGACGTTGCATGTTTCAGGAG;

NOX4 rev: AGCTGGTTCGGTTAAGACTGAT; 


\section{Cellular Physiology Cell Physiol Biochem 2018;46:1305-1316

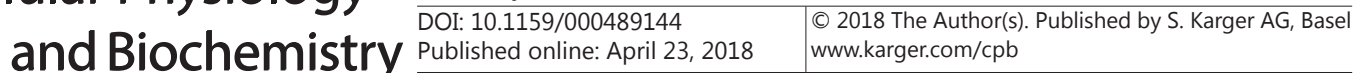 \\ Luong et al.: Fibulin-3 and Vascular Calcification}

PAI-1 fw: ACCGCAACGTGGTTTTCTCA;

$P A I-1$ rev: TTGAATCCCATAGCTGCTTGAAT;

SOX9 fw: AGCGAACGCACATCAAGAC;

SOX9 rev: CTGTAGGCGATCTGTTGGGG.

The specificity of the PCR products was confirmed by analysis of the melting curves. All PCRs were performed in duplicate and relative mRNA expression was calculated by the $2^{-\Delta \Delta C t}$ method using GAPDH as internal reference normalized to the control group.

\section{Western blot analysis}

HAoSMCs were lysed with ice-cold IP lysis buffer (Thermo Fisher Scientific) supplemented with complete protease and phosphatase inhibitor cocktail (Thermo Fisher Scientific) [44]. After centrifugation at $10000 \mathrm{rpm}$ for 5 minutes, the proteins were boiled in Roti-Load1 Buffer (Carl Roth $\mathrm{GmbH}$ ) at $100^{\circ} \mathrm{C}$ for $10 \mathrm{~min}$. Equal amounts of proteins were separated on SDS-polyacrylamide gels and transferred to PVDF membranes. The membranes were incubated overnight at $4^{\circ} \mathrm{C}$ with primary mouse anti-EFEMP1 antibody (diluted 1:1000, sc-33722, Santa Cruz Biotechnology) or rabbit anti-GAPDH antibody (diluted 1:5000, \#2118, Cell Signaling) and then with secondary anti-mouse HRP-conjugated (diluted 1:1000, Cell Signaling) or anti-rabbit HRP-conjugated antibody (diluted 1:1000, Cell Signaling) for 1 hour at RT. For loading controls, the membranes were stripped in stripping buffer (Thermo Fisher Scientific) at RT for 10 minutes. Antibody binding was detected with ECL detection reagent (Thermo Fisher Scientific). Bands were quantified by using ImageJ software and the results are shown as the ratio of total protein to GAPDH normalized to the control group.

\section{Statistics}

Data are shown as scatterdot plots and arithmetic means \pm SEM. $N$ indicates the number of independent experiments performed at different passages of the cells. Normality was tested with Shapiro-Wilk test. Non-normal datasets were transformed (log, reciprocal or sqrt) prior to statistical testing to provide normality according to Shapiro-Wilk test. Statistical testing was performed by one-way Anova followed by Tukey-test for homoscedastic data or Games-Howell test for heteroscedastic data. Non-normal data were tested by the Steel-Dwass method. Two groups were compared by unpaired two-tailed t-test. $\mathrm{P}<0.05$ was considered statistically significant.

\section{Results}

To investigate the effects of Fibulin-3 on phosphate-induced vascular calcification, a first series of experiments was performed in primary human aortic smooth muscle cells (HAoSMCs) following treatment with calcification media without or with additional treatment with recombinant human Fibulin-3 protein. As a result, Alizarin Red staining (Fig. 1A) and quantification of calcium deposition (Fig. 1B) in HAoSMCs revealed extensive calcification following treatment with calcification media, an effect significantly reduced by additional treatment with Fibulin-3. As shown in Fig. 1C-G, phosphate treatment significantly upregulated ALPL activity and the mRNA expression of osteogenic markers MSX2, CBFA1 and $A L P L$ and of chondrogenic marker SOX9 in HAoSMCs, all effects again significantly blunted by additional treatment with Fibulin-3. Treatment with Fibulin-3 alone did not significantly modify the calcium deposition and osteo-/chondrogenic markers expression in HAoSMCs (Fig. 1). Taken together, Fibulin-3 inhibits phosphate-induced osteo-/chondrogenic transdifferentiation and calcification of VSMCs in-vitro.

Additional experiments were performed to elucidate the underlying mechanisms of the protective effects of Fibulin-3 on VSMC calcification. Phosphate treatment did not significantly affect Fibulin-3 (encoded by the EFEMP1 gene) mRNA and protein expression in HAoSMCs (Fig. 2). Nonetheless, additional treatment with Fibulin-3 blunted the increased mRNA expression of NOX4 and p22phox (encoded by the CYBA gene) induced by high phosphate 


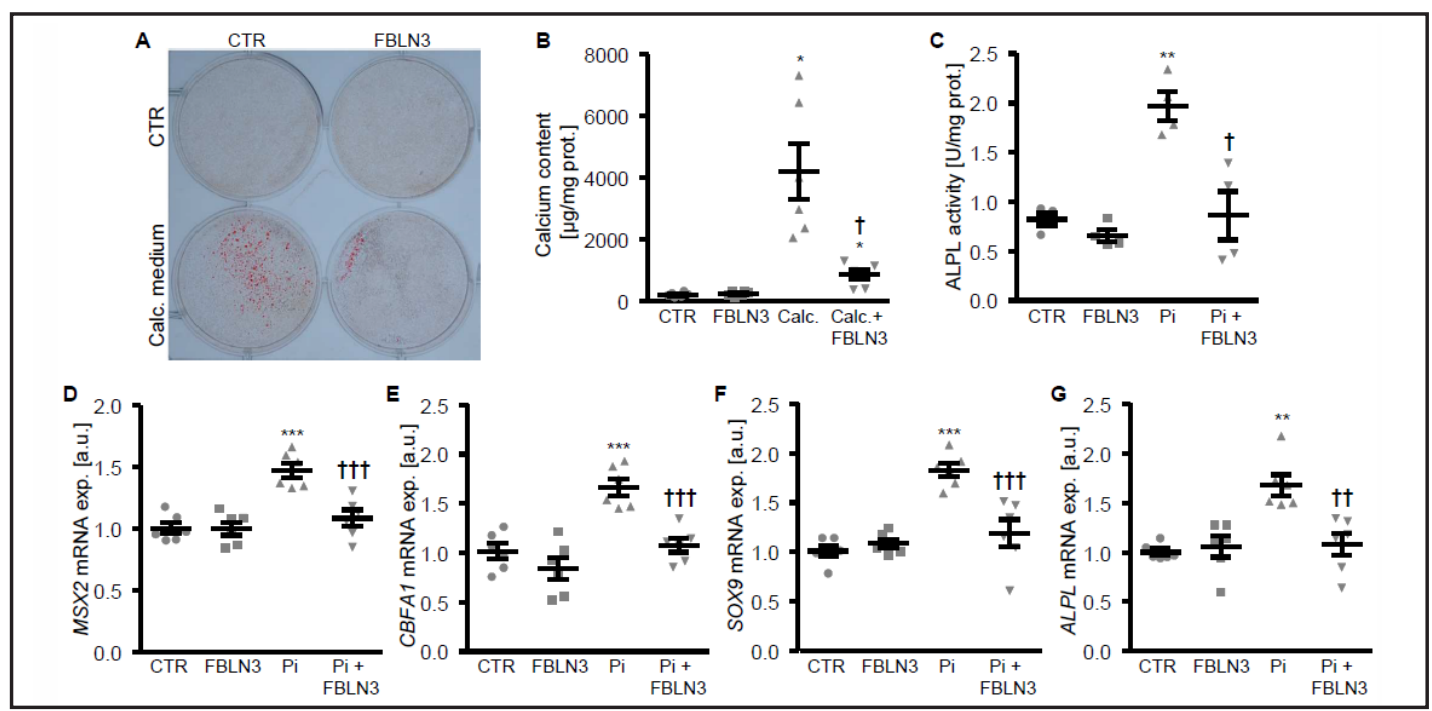

Fig. 1. Fibulin-3 inhibits phosphate-induced osteoinductive signaling and calcification in HAoSMCs. A. Representative original images showing Alizarin red staining in HAoSMCs following treatment for 11 days with control or with calcification medium (Calc.) without or with additional treatment with $200 \mathrm{ng} / \mathrm{ml} \mathrm{recom-}$ binant human Fibulin-3 protein. The calcified areas are shown as red staining. Images are representative for three independent experiments. B. Scatterdot plots and arithmetic means \pm SEM $(n=6, \mu \mathrm{g} / \mathrm{mg}$ protein) of calcium content in HAoSMCs following treatment for 11 days with control or with calcification medium (Calc.) without or with additional treatment with $200 \mathrm{ng} / \mathrm{ml}$ recombinant human Fibulin-3 protein. C. Scatterdot plots and arithmetic means \pm SEM $(n=4, U / m g$ protein) of ALPL activity in HAoSMCs following treatment for 7 days with control or with $2 \mathrm{mM} \beta$-glycerophosphate (Pi) without or with additional treatment with $200 \mathrm{ng} / \mathrm{ml}$ recombinant human Fibulin-3 protein. D-G. Scatterdot plots and arithmetic means \pm SEM (n=6; arbitrary units, a.u.) of MSX2 (D), CBFA1 (E), SOX9 (F) and ALPL (G) relative mRNA expression in HAoSMCs following treatment for 24 hours with control or with $2 \mathrm{mM} \beta$-glycerophosphate (Pi) without or with additional treatment with $200 \mathrm{ng} / \mathrm{ml}$ recombinant human Fibulin-3 protein. ${ }^{*}(\mathrm{p}<0.05),{ }^{* *}(\mathrm{p}<0.01)$, $* * *(p<0.001)$ statistically significant vs. control treated HAoSMCs; $\uparrow(\mathrm{p}<0.05),+\dagger(\mathrm{p}<0.01), \uparrow+\uparrow(\mathrm{p}<0.001)$ statistically significant vs. HAoSMCs treated with Calc./Pi alone.

Fig. 2. Fibulin-3 expression is not modified by phosphate in HAoSMCs. A. Scatterdot plots and arithmetic means \pm SEM ( $\mathrm{n}=6$; arbitrary units, a.u.) of EFEMP1 relative mRNA expression in HAoSMCs following treatment for 24 hours with control or with $2 \mathrm{mM} \beta$-glycerophosphate (Pi). B. Representative original Western blots and scatterdot plots and arithmetic

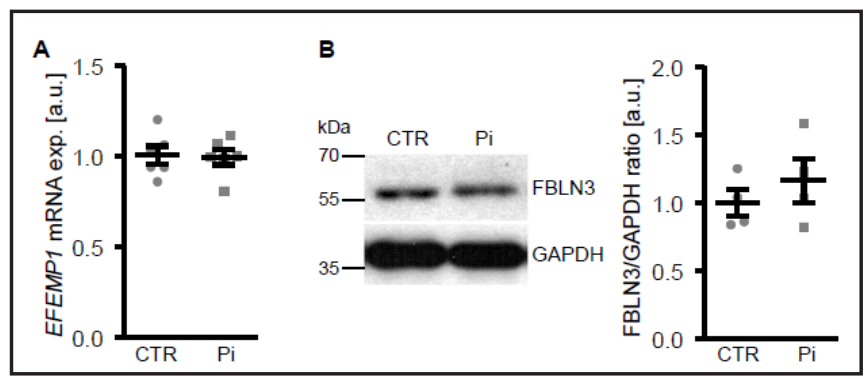
means \pm SEM ( $n=4$; a.u.) of normalized Fibulin-3/GAPDH protein ratio in HAoSMCs following treatment for 24 hours with control or with $2 \mathrm{mM} \beta$-glycerophosphate (Pi).

conditions in HAoSMCs, two critical components of the superoxide-generating NADH/NADPH oxidase system and markers of oxidative stress (Fig. 3A,B). Moreover, Fibulin-3 ameliorated the decrease of total antioxidant capacity in phosphate treated HAoSMCs (Fig. 3C). Thus, Fibulin-3 inhibits phosphate-induced oxidative stress in HAoSMCs.

These effects were paralleled by similar alteration of the oxidative stress downstream effectors in HAoSMCs. Phosphate treatment up-regulated the mRNA expression of plasminogen activator inhibitor PAI-1 (Fig. 4A) and of matrix gelatinases MMP2 and MMP9 (Fig. 4B,C) in HAoSMCs, all effects significantly reduced following additional treatment with Fibulin-3 protein. Furthermore, phosphate treatment induced indicators of apoptosis in 

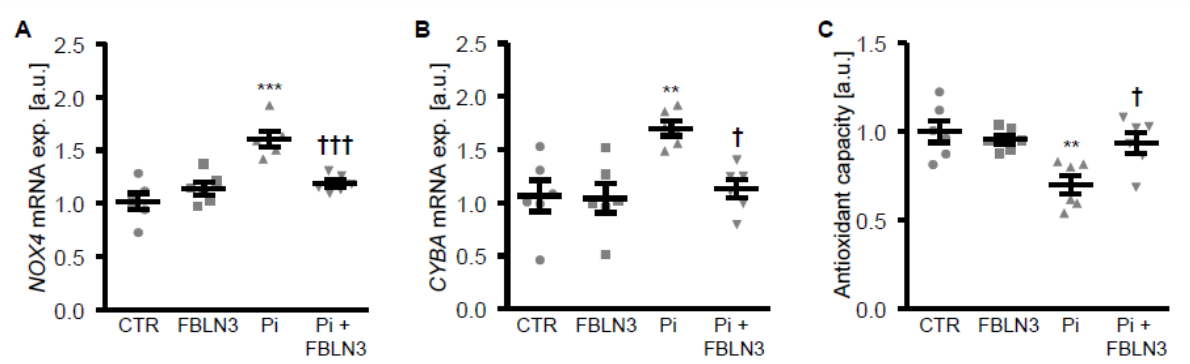

Fig. 3. Fibulin-3 attenuates phosphate-induced oxidative stress in HAoSMCs. A,B. Scatterdot plots and arithmetic means \pm SEM ( $\mathrm{n}=6$; arbitrary units, a.u.) of NOX4 (A) and CYBA (B) relative mRNA expression in HAoSMCs following treatment for 24 hours with control or with $2 \mathrm{mM} \beta$-glycerophosphate (Pi) without or with additional treatment with $200 \mathrm{ng} / \mathrm{ml}$ recombinant human Fibulin-3 protein. C. Scatter dot plots and arithmetic means \pm SEM ( $n=6$; a.u.) of normalized total antioxidant capacity of HAoSMCs following treatment for 24 hours with control or with $2 \mathrm{mM} \beta$-glycerophosphate (Pi) without or with additional treatment with $200 \mathrm{ng} / \mathrm{ml}$ recombinant human Fibulin-3 protein. ${ }^{* *}(\mathrm{p}<0.01),{ }^{* * *}(\mathrm{p}<0.001)$ statistically significant vs. control treated HAoSMCs; $\uparrow(p<0.05), ~ \dagger \dagger+(p<0.001)$ statistically significant vs. HAoSMCs treated with Pi alone.

Fig. 4. Fibulin-3 inhibits the expression of oxidative stress downstream effectors during high phosphate conditions in HAoSMCs. A-D. Scatterdot plots and arithmetic means \pm SEM ( $n=6$; arbitrary units, a.u.) of PAI-1 (A), MMP2 (B) and $M M P 9$ (C) relative mRNA expression as well as $B A X / B C L 2$ relative mRNA expression ratio (D) in HAoSMCs following treatment for 24 hours with control or with $2 \mathrm{mM}$ $\beta$-glycerophosphate (Pi) without or with additional treatment with $200 \mathrm{ng} / \mathrm{ml}$ recombinant human Fibulin-3 protein. ${ }^{*}(\mathrm{p}<0.05)$, $* * *(p<0.001)$ statistically significant vs. control treated HAoSMCs; $\dagger(\mathrm{p}<0.05), \quad+\dagger+(\mathrm{p}<0.001)$ statistically significant vs. HAoSMCs treated with Pi alone.
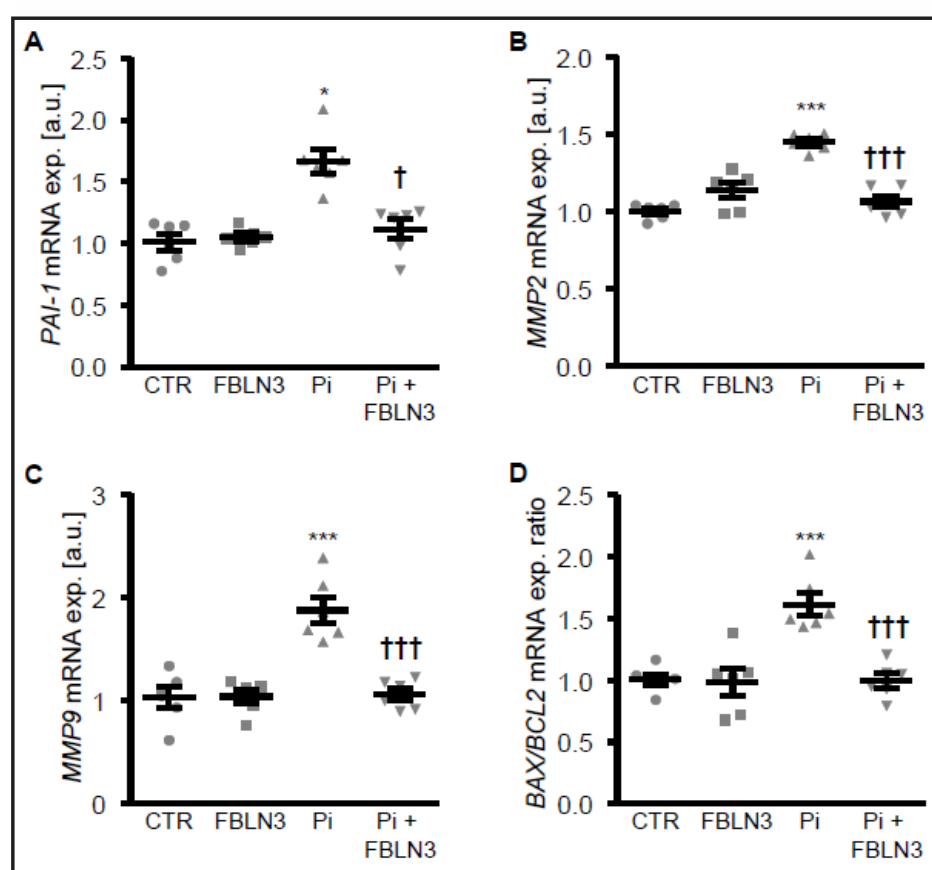

HAoSMCs, as shown by an increase in BAX/BCL2 mRNA expression ratio (Fig. 4D). These effects were again significantly ameliorated by Fibulin-3 treatment.

To further investigate whether inhibition of oxidative stress is responsible for the anti-calcific effects of Fibulin-3, low concentrations of $\mathrm{H}_{2} \mathrm{O}_{2}$ were added to HAoSMCs as an exogenous source of oxidative stress. As shown in Fig. 5, treatment with $\mathrm{H}_{2} \mathrm{O}_{2}$ alone significantly up-regulated MSX2, CBFA1, SOX9 and ALPL mRNA expression in HAoSMCs to similarly high levels as phosphate treatment and aggravated osteo-/chondrogenic markers expression in phosphate treated HAoSMCs (Fig. 5A-D) without significantly affecting EFEMP1 mRNA expression (Fig. 5E). More importantly, addition of $\mathrm{H}_{2} \mathrm{O}_{2}$ blocked the protective effects of Fibulin-3 on phosphate-induced osteo-/chondrogenic transdifferentiation of HAoSMCs (Fig. 5). Thus, the protective effects of Fibulin-3 on phosphate-induced osteo-/chondrogenic transdifferentiation of VSMCs are due, at least in part, to inhibition of endogenous oxidative stress. 


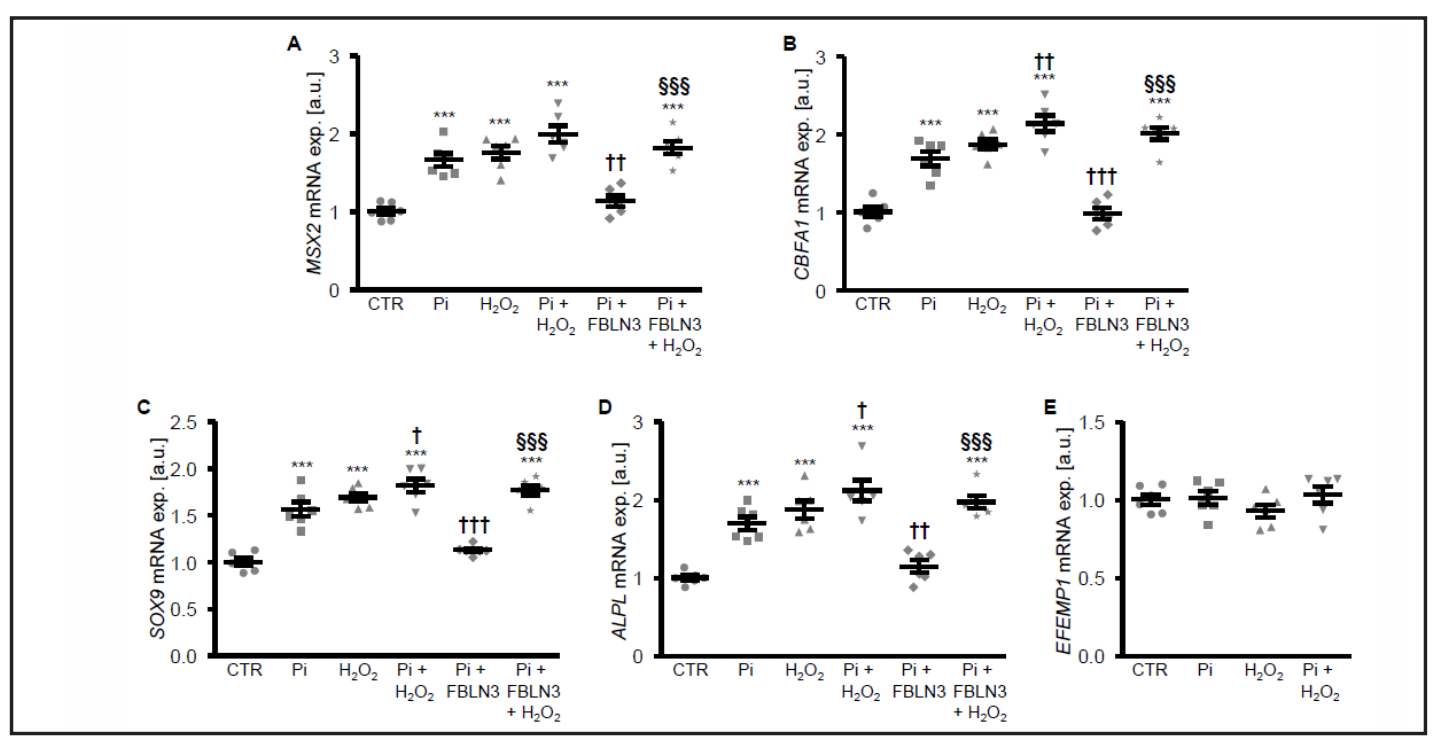

Fig. 5. The protective effects of Fibulin-3 on phosphate-induced osteoinduction are blunted by addition of $\mathrm{H}_{2} \mathrm{O}_{2}$ as an exogenous source of oxidative stress in HAoSMCs. A-D. Scatterdot plots and arithmetic means \pm SEM (n=6; arbitrary units, a.u.) of MSX2 (A), CBFA1 (B), SOX9 (C) and ALPL (D) relative mRNA expression in HAoSMCs following treatment for 24 hours with control, $2 \mathrm{mM} \beta$-glycerophosphate alone (Pi), 10 $\mu \mathrm{M} \mathrm{H}_{2} \mathrm{O}_{2}$ alone or $2 \mathrm{mM} \beta$-glycerophosphate together with $10 \mu \mathrm{M} \mathrm{H}_{2} \mathrm{O}_{2}\left(\mathrm{Pi}+\mathrm{H}_{2} \mathrm{O}_{2}\right), 200 \mathrm{ng} / \mathrm{ml}$ recombinant human Fibulin-3 protein (Pi+FBLN3) or $200 \mathrm{ng} / \mathrm{ml}$ recombinant human Fibulin-3 protein and $10 \mu \mathrm{M} \mathrm{H}_{2} \mathrm{O}_{2}$ $\left(\mathrm{Pi}+\mathrm{FBLN} 3+\mathrm{H}_{2} \mathrm{O}_{2}\right) .{ }^{* * *}(\mathrm{p}<0.001)$ statistically significant vs. control treated HAoSMCs; $\uparrow(\mathrm{p}<0.05), \dagger+(\mathrm{p}<0.01)$, $\dagger+\dagger(\mathrm{p}<0.001)$ statistically significant vs. HAoSMCs treated with Pi alone; $\S \S \S(\mathrm{p}<0.001)$ statistically significant between Pi+FBLN3 and Pi+FBLN3 $+\mathrm{H}_{2} \mathrm{O}_{2}$ HAoSMCs. E. Scatterdot plots and arithmetic means \pm SEM (n=6; a.u.) of EFEMP1 relative mRNA expression in HAoSMCs following treatment for 24 hours with control, $2 \mathrm{mM} \beta$-glycerophosphate alone (Pi), $10 \mu \mathrm{M} \mathrm{H}_{2} \mathrm{O}_{2}$ alone or $2 \mathrm{mM} \beta$-glycerophosphate together with $10 \mu \mathrm{M}$ $\mathrm{H}_{2} \mathrm{O}_{2}\left(\mathrm{Pi}+\mathrm{H}_{2} \mathrm{O}_{2}\right)$.

\section{Discussion}

The present study reveals a novel role of Fibulin-3 in the inhibition of osteo-/ chondrogenic transdifferentiation and calcification of VSMCs during hyperphosphatemia in-vitro. Fibulin-3 treatment blunts phosphate-induced oxidative stress, while addition of an exogenous source of oxidative stress suppresses the anti-calcific effects of Fibulin-3 in VSMCs.

Oxidative stress represents the imbalance between antioxidant systems and oxidative products [20]. Phosphate up-regulates the expression of NOX4 and CYBA, two critical components of the superoxide-generating NADH/NADPH oxidase system $[48,49]$ and reduces total antioxidant capacity of VSMCs. Fibulin-3 supplementation is able to suppress the expression of NADH/NADPH oxidase system components and may, thus, interfere with reactive oxygen species production in VSMCs. In accordance with previous observations [10], Fibulin-3 treatment is able to block the accumulation of oxidative stress in phosphate treated VSMCs.

Excessive oxidative stress is involved in the pathogenesis of vascular calcification $[20,28-30]$. Reactive oxygen species are mediators of CKD-related vascular calcification $[48,50]$. Similarly, increased NADPH oxidase activity is associated with coronary artery calcification in asymptomatic men [49]. Oxidative stress contributes to the progression of vascular calcification via active cellular mechanisms by stimulating osteo-/chondrogenic transdifferentiation of VSMCs [29, 50]. Accordingly, hydrogen peroxide induces the phenotypical transformation of VSMCs into osteoblast-like cells, including up-regulation of CBFA1 expression [29] and ALPL activity [30] to facilitate mineral deposition. Conversely, 
antioxidants are able to reduce osteo-/chondrogenic transdifferentiation and calcification of VSMCs [51]. The present data shows that Fibulin-3 suppresses the increased expression of osteogenic transcription factors MSX2 and CBFA1 and of chondrogenic transcription factor SOX9 as well as ALPL expression and activity in VSMCs following high phosphate treatment. Previous studies similarly show that Fibulin-3 is able to reduce SOX9 expression and to inhibit chondrogenesis in bone marrow-derived mesenchymal stem cells as well as differentiation of chondrocytes $[52,53]$.

Downstream effectors of oxidative stress in VSMCs include plasminogen activator inhibitor PAI-1 [16, 54] and the matrix metalloproteinases MMP2 and MMP9, also known as gelatinases [14-17, 55]. The increased PAI-1 expression, a regulator of VSMCs calcification $[28,56]$, is attenuated by Fibulin-3 during high phosphate conditions. Similarly, Fibulin-3 reduces phosphate-induced MMP2 and MMP9 expression in VSMCs. Gelatinases are essential for phenotypical transformation of VSMCs, matrix remodeling and initiation of vascular calcification $[57,58]$ by up-regulation of bone morphogenetic protein-2 (BMP-2) which induces the expression of CBFA1 and MSX2 [59]. Furthermore, oxidative stress is able to induce apoptosis of VSMCs [60] and apoptosis may promote the initiation and progression of vascular calcification [61]. Accordingly, Fibulin-3 is able to inhibit phosphate-induced increase in $B A X / B C L 2$ ratio in VSMCs, a maker of increased apoptosis.

The inhibitory effect of Fibulin-3 on phosphate-induced osteogenic and chondrogenic markers expression in VSMCs is blunted by additional treatment with low concentrations of hydrogen peroxide. Thus, in the presence of an exogenous source of oxidative stress, Fibulin-3 fails to inhibit the osteo-/chondrogenic signaling in VSMCs. Taken together, the present observations suggest that Fibulin-3 may be effective not by interfering with oxidative stress-downstream osteoinductive signaling in VSMCs, but rather by interfering with reactive oxygen species production and accumulation of oxidative stress in VSMCs. Excessive oxidative stress does not modify Fibulin-3 expression in VSMCs. However, oxidation may render Fibulin-3 biologically inactive [1, 2, 62-64]. Further studies are clearly required to elucidate whether Fibulin-3 function is affected by calcific conditions in VSMCs. Nonetheless, the current observations suggest that Fibulin-3 supplementation reduces osteo-/chondrogenic signaling in VSMCs and, thus, vascular calcification, effects involving inhibition of endogenous oxidative stress.

In addition, other mechanisms may contribute to the anti-calcific effects of Fibulin-3 in the vascular tissue. Fibulin-3 may hinder extracellular matrix remodeling and elastin degradation $[4,5,61,65,66]$. Furthermore, Fibulin-3 may interfere with various intracellular signaling pathways [7-9] in vascular calcification. Fibulin-3 was previously shown to be an inhibitor of TGF- $\beta$-dependent signaling [9], a key intracellular pathway in osteo-/ chondrogenic transdifferentiation of VSMCs $[67,68]$. However, addition of Fibulin-3 failed to suppress the TGF- $\beta$-dependent osteoinductive signaling in VSMCs (data not shown).

Despite the finding that phosphate did not directly affect Fibulin-3 expression in VSMCs, the present observations suggest that Fibulin-3 may reduce the progression of vascular calcification in conditions of hyperphosphatemia such as CKD [21, 27]. In these patients, oxidative stress is further associated with increased cardiovascular and all-cause mortality [18-20] and thus, Fibulin-3 may have overall protective effects in systemic changes during disease progression. However, Fibulin-3 may promote neoplastic growth in some tumors [69, 70]. Also, tumor suppressive properties of Fibulin-3 were described [71]. These observations warrant caution and further investigations of a possible safe further translation of Fibulin-3 treatment in CKD patients [72].

In theory, Fibulin-3 may be effective in reducing vascular calcification in other pathologies associated with oxidative stress such as diabetes mellitus $[73,74]$ or aging $[28$, 75]. Fibulin-3 expression is decreased with aging [52] and Fibulin-3 deficiency in mice leads to early onset of aging-associated phenotypes [76]. Further studies are necessary to confirm the potential benefits of Fibulin-3 in these conditions.

In conclusion, Fibulin-3 reduces phosphate-induced osteo-/chondrogenic transdifferentiation of VSMCs and, thus, vascular calcification by inhibiting endogenous 
oxidative stress. The present observations reveal that up-regulation or supplementation of Fibulin-3 may be beneficial in reducing the progression of vascular calcification during high phosphate conditions such as CKD.

\section{Acknowledgements}

This work was supported by the European Union Seventh Framework Programme (FP7/2007-2013-603288-SysVasc), the Berlin Institute of Health (BIH) Translational Postdoc Grant, the Deutsche Forschungsgemeinschaft (AL2054/1-1, V02259/2-1) and the Else Kröner-Fresenius-Stiftung.

\section{Disclosure Statement}

All authors disclose that they have no potential conflict of interest.

\section{References}

1 Giltay R, Timpl R, Kostka G: Sequence, recombinant expression and tissue localization of two novel extracellular matrix proteins, fibulin-3 and fibulin-4. Matrix Biol 1999;18:469-480.

-2 Kobayashi N, Kostka G, Garbe JH, Keene DR, Bachinger HP, Hanisch FG, Markova D, Tsuda T, Timpl R, Chu ML, Sasaki T: A comparative analysis of the fibulin protein family. Biochemical characterization, binding interactions, and tissue localization. J Biol Chem 2007;282:11805-11816.

-3 Lin ZW, Wang Z, Zhu GP, Li BW, Xie WL, Xiang DC: Hypertensive vascular remodeling was inhibited by Xuezhikang through the regulation of Fibulin-3 and MMPs in spontaneously hypertensive rats. Int J Clin Exp Med 2015;8:2118-2127.

4 Zhang Y, Marmorstein LY: Focus on molecules: fibulin-3 (EFEMP1). Exp Eye Res 2010;90:374-375.

5 Argraves WS, Greene LM, Cooley MA, Gallagher WM: Fibulins: physiological and disease perspectives. EMBO Rep 2003;4:1127-1131.

-6 Nandhu MS, Hu B, Cole SE, Erdreich-Epstein A, Rodriguez-Gil DJ, Viapiano MS: Novel paracrine modulation of Notch-DLL4 signaling by fibulin-3 promotes angiogenesis in high-grade gliomas. Cancer Res 2014;74:5435-5448.

7 Camaj P, Seeliger H, Ischenko I, Krebs S, Blum H, De Toni EN, Faktorova D, Jauch KW, Bruns CJ: EFEMP1 binds the EGF receptor and activates MAPK and Akt pathways in pancreatic carcinoma cells. Biol Chem 2009;390:1293-1302.

-8 Chen X, Meng J, Yue W, Yu J, Yang J, Yao Z, Zhang L: Fibulin-3 suppresses Wnt/beta-catenin signaling and lung cancer invasion. Carcinogenesis 2014;35:1707-1716.

-9 Tian H, Liu J, Chen J, Gatza ML, Blobe GC: Fibulin-3 is a novel TGF-beta pathway inhibitor in the breast cancer microenvironment. Oncogene 2015;34:5635-5647.

10 Lin Z, Wang Z, Li G, Li B, Xie W, Xiang D: Fibulin-3 may improve vascular health through inhibition of MMP2/9 and oxidative stress in spontaneously hypertensive rats. Mol Med Rep 2016;13:3805-3812.

-11 Togliatto G, Lombardo G, Brizzi MF: The Future Challenge of Reactive Oxygen Species (ROS) in Hypertension: From Bench to Bed Side. Int J Mol Sci 2017;18

12 Varadharaj S, Kelly OJ, Khayat RN, Kumar PS, Ahmed N, Zweier JL: Role of Dietary Antioxidants in the Preservation of Vascular Function and the Modulation of Health and Disease. Front Cardiovasc Med 2017;4:64.

13 Kim EJ, Lee SY, Woo MK, Choi SI, Kim TR, Kim MJ, Kim KC, Cho EW, Kim IG: Fibulin-3 promoter methylation alters the invasive behavior of non-small cell lung cancer cell lines via MMP-7 and MMP-2 regulation. Int J Oncol 2012;40:402-408.

14 Belo VA, Guimaraes DA, Castro MM: Matrix Metalloproteinase 2 as a Potential Mediator of Vascular Smooth Muscle Cell Migration and Chronic Vascular Remodeling in Hypertension. J Vasc Res 2015;52:221-231. 


\section{Cellular Physiology Cell Physiol Biochem 2018;46:1305-1316 \begin{tabular}{l|l} 
DOI: 10.1159/000489144 & $\begin{array}{l}\text { O 2018 The Author(s). Published by S. Karger AG, Basel } \\
\text { wwww.karger.com/cpb }\end{array}$
\end{tabular}}

15 Moon SK, Kang SK, Kim CH: Reactive oxygen species mediates disialoganglioside GD3-induced inhibition of ERK1/2 and matrix metalloproteinase-9 expression in vascular smooth muscle cells. FASEB J 2006;20:1387-1395.

16 Tobar N, Villar V, Santibanez JF: ROS-NFkappaB mediates TGF-beta1-induced expression of urokinase-type plasminogen activator, matrix metalloproteinase-9 and cell invasion. Mol Cell Biochem 2010;340:195-202.

17 Valentin F, Bueb JL, Kieffer P, Tschirhart E, Atkinson J: Oxidative stress activates MMP-2 in cultured human coronary smooth muscle cells. Fundam Clin Pharmacol 2005;19:661-667.

18 Poulianiti KP, Kaltsatou A, Mitrou GI, Jamurtas AZ, Koutedakis Y, Maridaki M, Stefanidis I, Sakkas GK, Karatzaferi C: Systemic Redox Imbalance in Chronic Kidney Disease: A Systematic Review. Oxid Med Cell Longev 2016;2016:8598253.

19 Tucker PS, Scanlan AT, Dalbo VJ: Chronic kidney disease influences multiple systems: describing the relationship between oxidative stress, inflammation, kidney damage, and concomitant disease. Oxid Med Cell Longev 2015;2015:806358.

20 Liakopoulos V, Roumeliotis S, Gorny X, Dounousi E, Mertens PR: Oxidative Stress in Hemodialysis Patients: A Review of the Literature. Oxid Med Cell Longev 2017;2017:3081856.

21 Shroff R, Long DA, Shanahan C: Mechanistic insights into vascular calcification in CKD. J Am Soc Nephrol 2013;24:179-189.

22 Lanzer P, Boehm M, Sorribas V, Thiriet M, Janzen J, Zeller T, St Hilaire C, Shanahan C: Medial vascular calcification revisited: review and perspectives. Eur Heart J 2014;35:1515-1525.

23 Steitz SA, Speer MY, Curinga G, Yang HY, Haynes P, Aebersold R, Schinke T, Karsenty G, Giachelli CM: Smooth muscle cell phenotypic transition associated with calcification: upregulation of $\mathrm{Cbfa} 1$ and downregulation of smooth muscle lineage markers. Circ Res 2001;89:1147-1154.

24 Chen NX, Moe SM: Pathophysiology of Vascular Calcification. Curr Osteoporos Rep 2015;13:372-380.

-25 Lang F, Ritz E, Alesutan I, Voelkl J: Impact of aldosterone on osteoinductive signaling and vascular calcification. Nephron Physiol 2014;128:40-45.

-26 Lang F, Ritz E, Voelkl J, Alesutan I: Vascular calcification--is aldosterone a culprit? Nephrol Dial Transplant 2013;28:1080-1084.

27 Giachelli CM: The emerging role of phosphate in vascular calcification. Kidney Int 2009;75:890-897.

28 Alesutan I, Feger M, Tuffaha R, Castor T, Musculus K, Buehling SS, Heine CL, Kuro OM, Pieske B, Schmidt K, Tomaschitz A, Maerz W, Pilz S, Meinitzer A, Voelkl J, Lang F: Augmentation of phosphate-induced osteo-/chondrogenic transformation of vascular smooth muscle cells by homoarginine. Cardiovasc Res 2016;110:408-418.

29 Byon CH, Javed A, Dai Q, Kappes JC, Clemens TL, Darley-Usmar VM, McDonald JM, Chen Y: Oxidative stress induces vascular calcification through modulation of the osteogenic transcription factor Runx2 by AKT signaling. J Biol Chem 2008;283:15319-15327.

-30 Mody N, Parhami F, Sarafian TA, Demer LL: Oxidative stress modulates osteoblastic differentiation of vascular and bone cells. Free Radic Biol Med 2001;31:509-519.

-31 Cheng SL, Behrmann A, Shao JS, Ramachandran B, Krchma K, Bello Arredondo Y, Kovacs A, Mead M, Maxson $\mathrm{R}$, Towler DA: Targeted reduction of vascular Msx1 and Msx2 mitigates arteriosclerotic calcification and aortic stiffness in LDLR-deficient mice fed diabetogenic diets. Diabetes 2014;63:4326-4337.

-32 Xu Z, Ji G, Shen J, Wang X, Zhou J, Li L: SOX9 and myocardin counteract each other in regulating vascular smooth muscle cell differentiation. Biochem Biophys Res Commun 2012;422:285-290.

-33 Sheen CR, Kuss P, Narisawa S, Yadav MC, Nigro J, Wang W, Chhea TN, Sergienko EA, Kapoor K, Jackson MR, Hoylaerts MF, Pinkerton AB, O'Neill WC, Millan JL: Pathophysiological role of vascular smooth muscle alkaline phosphatase in medial artery calcification. J Bone Miner Res 2015;30:824-836.

34 Alesutan I, Musculus K, Castor T, Alzoubi K, Voelkl J, Lang F: Inhibition of Phosphate-Induced Vascular Smooth Muscle Cell Osteo-/Chondrogenic Signaling and Calcification by Bafilomycin A1 and Methylamine. Kidney Blood Press Res 2015;40:490-499.

-35 Alesutan I, Voelkl J, Feger M, Kratschmar DV, Castor T, Mia S, Sacherer M, Viereck R, Borst O, Leibrock C, Gawaz M, Kuro OM, Pilz S, Tomaschitz A, Odermatt A, Pieske B, Wagner CA, Lang F: Involvement Of Vascular Aldosterone Synthase In Phosphate-Induced Osteogenic Transformation Of Vascular Smooth Muscle Cells. Sci Rep 2017;7:2059.

-36 Chung CH, Golub EE, Forbes E, Tokuoka T, Shapiro IM: Mechanism of action of beta-glycerophosphate on bone cell mineralization. Calcif Tissue Int 1992;51:305-311. 


\section{Cellular Physiology Cell Physiol Biochem 2018;46:1305-1316 \begin{tabular}{ll|l} 
and Biochemistry $10.1159 / 000489144$ & $\begin{array}{l}\text { Dublished online: April 23, } 2018 \\
\text { www.karger.com/cpb }\end{array}$ \\
\hline
\end{tabular}}

Luong et al.: Fibulin-3 and Vascular Calcification

-37 Liao XB, Zhang ZY, Yuan K, Liu Y, Feng X, Cui RR, Hu YR, Yuan ZS, Gu L, Li SJ, Mao DA, Lu Q Zhou XM, de Jesus Perez VA, Yuan LQ: MiR-133a modulates osteogenic differentiation of vascular smooth muscle cells. Endocrinology 2013;154:3344-3352.

-38 Qiao W, Chen L, Zhang M: MicroRNA-205 regulates the calcification and osteoblastic differentiation of vascular smooth muscle cells. Cell Physiol Biochem 2014;33:1945-1953.

-39 Dou CY, Cao CJ, Wang Z, Zhang RH, Huang LL, Lian JY, Xie WL, Wang LT: EFEMP1 inhibits migration of hepatocellular carcinoma by regulating MMP2 and MMP9 via ERK1/2 activity. Oncol Rep 2016;35:34893495.

-40 Luo T, Xia Z: A small dose of hydrogen peroxide enhances tumor necrosis factor-alpha toxicity in inducing human vascular endothelial cell apoptosis: reversal with propofol. Anesth Analg 2006;103:110-116, table of contents.

41 Graham S, Ding M, Ding Y, Sours-Brothers S, Luchowski R, Gryczynski Z, Yorio T, Ma H, Ma R: Canonical transient receptor potential 6 (TRPC6), a redox-regulated cation channel. J Biol Chem 2010;285:2346623476.

42 Byon CH, Heath JM, Chen Y: Redox signaling in cardiovascular pathophysiology: A focus on hydrogen peroxide and vascular smooth muscle cells. Redox Biol 2016;9:244-253.

43 Villa-Bellosta R, Millan A, Sorribas V: Role of calcium-phosphate deposition in vascular smooth muscle cell calcification. Am J Physiol Cell Physiol 2011;300:C210-220.

44 Alesutan I, Tuffaha R, Auer T, Feger M, Pieske B, Lang F, Voelkl J: Inhibition of osteo/chondrogenic transformation of vascular smooth muscle cells by $\mathrm{MgCl} 2$ via calcium-sensing receptor. J Hypertens 2017;35:523-532.

45 Voelkl J, Alesutan I, Leibrock CB, Quintanilla-Martinez L, Kuhn V, Feger M, Mia S, Ahmed MS, Rosenblatt KP, Kuro OM, Lang F: Spironolactone ameliorates PIT1-dependent vascular osteoinduction in klothohypomorphic mice. J Clin Invest 2013;123:812-822.

-46 Voelkl J, Pakladok T, Lin Y, Viereck R, Lebedeva A, Kukuk D, Pichler BJ, Alesutan I, Lang F: Up-regulation of hepatic alpha-2-HS-glycoprotein transcription by testosterone via androgen receptor activation. Cell Physiol Biochem 2014;33:1911-1920.

47 Voelkl J, Alesutan I, Primessnig U, Feger M, Mia S, Jungmann A, Castor T, Viereck R, Stockigt F, Borst O, Gawaz M, Schrickel JW, Metzler B, Katus HA, Muller OJ, Pieske B, Heinzel FR, Lang F: AMP-activated protein kinase alpha1-sensitive activation of AP-1 in cardiomyocytes. J Mol Cell Cardiol 2016;97:36-43.

48 Agharazii M, St-Louis R, Gautier-Bastien A, Ung RV, Mokas S, Lariviere R, Richard DE: Inflammatory cytokines and reactive oxygen species as mediators of chronic kidney disease-related vascular calcification. Am J Hypertens 2015;28:746-755.

49 Beloqui O, Moreno MU, San Jose G, Pejenaute A, Cortes A, Landecho MF, Diez J, Fortuno A, Zalba G: Increased phagocytic NADPH oxidase activity associates with coronary artery calcification in asymptomatic men. Free Radic Res 2017;51:389-396.

50 Mizobuchi M, Towler D, Slatopolsky E: Vascular calcification: the killer of patients with chronic kidney disease. J Am Soc Nephrol 2009;20:1453-1464.

51 Yamada S, Taniguchi M, Tokumoto M, Toyonaga J, Fujisaki K, Suehiro T, Noguchi H, Iida M, Tsuruya K, Kitazono T: The antioxidant tempol ameliorates arterial medial calcification in uremic rats: important role of oxidative stress in the pathogenesis of vascular calcification in chronic kidney disease. J Bone Miner Res 2012;27:474-485.

52 Hasegawa A, Yonezawa T, Taniguchi N, Otabe K, Akasaki Y, Matsukawa T, Saito M, Neo M, Marmorstein LY, Lotz MK: Role of Fibulin 3 in Aging-Related Joint Changes and Osteoarthritis Pathogenesis in Human and Mouse Knee Cartilage. Arthritis Rheumatol 2017;69:576-585.

53 Wakabayashi T, Matsumine A, Nakazora S, Hasegawa M, Iino T, Ota H, Sonoda H, Sudo A, Uchida A: Fibulin-3 negatively regulates chondrocyte differentiation. Biochem Biophys Res Commun 2010;391:1116-1121.

54 Sato H, Sato M, Kanai H, Uchiyama T, Iso T, Ohyama Y, Sakamoto H, Tamura J, Nagai R, Kurabayashi M: Mitochondrial reactive oxygen species and c-Src play a critical role in hypoxic response in vascular smooth muscle cells. Cardiovasc Res 2005;67:714-722.

55 Cheng Z, Limbu MH, Wang Z, Liu J, Liu L, Zhang X, Chen P, Liu B: MMP-2 and 9 in Chronic Kidney Disease. Int J Mol Sci 2017;18

56 Kanno Y, Into T, Lowenstein CJ, Matsushita K: Nitric oxide regulates vascular calcification by interfering with TGF- signalling. Cardiovasc Res 2008;77:221-230. 


\section{Cellular Physiology Cell Physiol Biochem 2018;46:1305-1316 \begin{tabular}{l|l} 
DOI: 10.1159/000489144 & $\begin{array}{l}\text { O 2018 The Author(s). Published by S. Karger AG, Basel } \\
\text { www.karger.com/cpb }\end{array}$ \\
\hline
\end{tabular}}

Luong et al.: Fibulin-3 and Vascular Calcification

-57 Chen NX, O'Neill KD, Chen X, Kiattisunthorn K, Gattone VH, Moe SM: Activation of arterial matrix metalloproteinases leads to vascular calcification in chronic kidney disease. Am J Nephrol 2011;34:211219.

58 Hecht E, Freise C, Websky KV, Nasser H, Kretzschmar N, Stawowy P, Hocher B, Querfeld U: The matrix metalloproteinases 2 and 9 initiate uraemic vascular calcifications. Nephrol Dial Transplant 2016;31:789797.

59 Zhao YG, Meng FX, Li BW, Sheng YM, Liu MM, Wang B, Li HW, Xiu RJ: Gelatinases promote calcification of vascular smooth muscle cells by up-regulating bone morphogenetic protein-2. Biochem Biophys Res Commun 2016;470:287-293.

60 Gomez C, Martinez L, Mesa A, Duque JC, Escobar LA, Pham SM, Vazquez-Padron RI: Oxidative stress induces early-onset apoptosis of vascular smooth muscle cells and neointima formation in response to injury. Biosci Rep 2015;35

61 Paloian NJ, Giachelli CM: A current understanding of vascular calcification in CKD. Am J Physiol Renal Physiol 2014;307:F891-900.

62 Starke-Reed PE, Oliver CN: Protein oxidation and proteolysis during aging and oxidative stress. Arch Biochem Biophys 1989;275:559-567.

63 Nandhu MS, Behera P, Bhaskaran V, Longo SL, Barrera-Arenas LM, Sengupta S, Rodriguez-Gil DJ, Chiocca EA, Viapiano MS: Development of a Function-Blocking Antibody Against Fibulin-3 as a Targeted Reagent for Glioblastoma. Clin Cancer Res 2018;24:821-833.

64 Henrotin Y, Gharbi M, Mazzucchelli G, Dubuc JE, De Pauw E, Deberg M: Fibulin 3 peptides Fib3-1 and Fib3-2 are potential biomarkers of osteoarthritis. Arthritis Rheum 2012;64:2260-2267.

-65 Hsu JJ, Lim J, Tintut Y, Demer LL: Cell-matrix mechanics and pattern formation in inflammatory cardiovascular calcification. Heart 2016;102:1710-1715.

66 Pai AS, Giachelli CM: Matrix remodeling in vascular calcification associated with chronic kidney disease. J Am Soc Nephrol 2010;21:1637-1640.

67 Leibrock CB, Alesutan I, Voelkl J, Pakladok T, Michael D, Schleicher E, Kamyabi-Moghaddam Z, QuintanillaMartinez L, Kuro-o M, Lang F: NH4Cl Treatment Prevents Tissue Calcification in Klotho Deficiency. J Am Soc Nephrol 2015;26:2423-2433.

68 Tachi K, Takami M, Sato H, Mochizuki A, Zhao B, Miyamoto Y, Tsukasaki H, Inoue T, Shintani S, Koike T, Honda Y, Suzuki O, Baba K, Kamijo R: Enhancement of bone morphogenetic protein-2-induced ectopic bone formation by transforming growth factor-beta1. Tissue Eng Part A 2011;17:597-606.

69 Han AL, Veeneman BA, El-Sawy L, Day KC, Day ML, Tomlins SA, Keller ET: Fibulin-3 promotes muscleinvasive bladder cancer. Oncogene 2017;36:5243-5251.

70 Hu B, Nandhu MS, Sim H, Agudelo-Garcia PA, Saldivar JC, Dolan CE, Mora ME, Nuovo GJ, Cole SE, Viapiano MS: Fibulin-3 promotes glioma growth and resistance through a novel paracrine regulation of Notch signaling. Cancer Res 2012;72:3873-3885.

71 Kim IG, Kim SY, Choi SI, Lee JH, Kim KC, Cho EW: Fibulin-3-mediated inhibition of epithelial-tomesenchymal transition and self-renewal of ALDH+ lung cancer stem cells through IGF1R signaling. Oncogene 2014;33:3908-3917.

-72 Chaykovska L, Tsuprykov 0, Hocher B: Biomarkers for the prediction of mortality and morbidity in patients with renal replacement therapy. Clin Lab 2011;57:455-467.

73 Dounousi E, Duni A, Leivaditis K, Vaios V, Eleftheriadis T, Liakopoulos V: Improvements in the Management of Diabetic Nephropathy. Rev Diabet Stud 2015;12:119-133.

74 Giugliano D, Ceriello A, Paolisso G: Oxidative stress and diabetic vascular complications. Diabetes Care 1996;19:257-267.

75 Harvey A, Montezano AC, Touyz RM: Vascular biology of ageing-Implications in hypertension. J Mol Cell Cardiol 2015;83:112-121.

76 McLaughlin PJ, Bakall B, Choi J, Liu Z, Sasaki T, Davis EC, Marmorstein AD, Marmorstein LY: Lack of fibulin-3 causes early aging and herniation, but not macular degeneration in mice. Hum Mol Genet 2007;16:30593070 . 